\title{
Factors affecting the relationship between ionized and corrected calcium levels in peritoneal dialysis patients: a retrospective cross-sectional study
}

Masamitsu Morishita*, Yukio Maruyama, Masatsugu Nakao, Nanae Matsuo, Yudo Tanno, Ichiro Ohkido, Masato Ikeda and Takashi Yokoo

\begin{abstract}
Background: Chronic kidney disease-mineral and bone disorder (CKD-MBD) management in patients with endstage renal disease is important owing to the risk of cardiovascular diseases. In clinical practice, we manage patients not by monitoring the levels of biologically active ionized calcium (iCa) but by monitoring total serum calcium or corrected calcium (cCa). We previously reported that $\mathrm{iCa} / \mathrm{cCa}$ ratio was different between patients with hemodialysis and those with peritoneal dialysis (PD). In PD patients, several factors are expected to affect iCa/cCa ratio. Therefore, modifying the strategy to achieve better CKD-MBD management might be necessary; however, no reports have studied this to date. Therefore, we investigated the factors influencing $\mathrm{iCa} / \mathrm{cCa}$ ratio in PD patients.

Methods: This retrospective cross-sectional study examined background and laboratory data, including iCa, collected at routine outpatient visits. The patients were divided into the first, second, and third tertile of $\mathrm{iCa} / \mathrm{cCa}$ ratio groups to compare patient background and laboratory data. Multiple regression analysis was used to investigate the factors influencing iCa/cCa ratio. We used multiple imputation to deal with missing covariate data.

Results: In total, 169 PD patients were enrolled. In PD patients with lower iCa/cCa ratio, PD duration was longer and $\mathrm{pH}$ was higher. Urine volume and weekly renal $\mathrm{Kt} / \mathrm{N}$ were lower in the patients with lower $\mathrm{iCa} / \mathrm{CC}$ ratio than in those with higher $\mathrm{iCa} / \mathrm{cCa}$ ratio. iCa/cCa ratio and weekly renal $\mathrm{Kt} / \mathrm{N}$ were directly correlated $(r=0.41, p<0.01)$, and weekly renal $\mathrm{Kt} / \mathrm{N}$ and $\mathrm{pH}$ were independent factors affecting $\mathrm{iCa} / \mathrm{cCa}$ ratio $(\mathrm{t}=2.86, p<0.01$ and $\mathrm{t}=-5.42, p<0.01$, respectively).
\end{abstract}

Conclusions: iCa levels were lower in PD patients with lower residual renal function (RRF) even though their CCa levels were equal to those with maintained RRF, warranting caution in the assessment and management of CKDMBD in PD patients.

Keywords: Peritoneal dialysis, Chronic kidney disease-mineral and bone disorder, Corrected calcium, lonized calcium, Acid-base equilibrium, Residual renal function

\footnotetext{
*Correspondence: m.morishita0319@gmail.com

Division of Nephrology and Hypertension, Department of Internal Medicine,

The Jikei University School of Medicine, 3-25-8 Nishi-shinbashi, Minato-ku,

Tokyo 105-8461, Japan
}

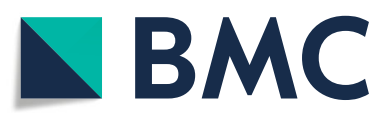

(0) The Author(s). 2020 Open Access This article is licensed under a Creative Commons Attribution 4.0 International License, which permits use, sharing, adaptation, distribution and reproduction in any medium or format, as long as you give appropriate credit to the original author(s) and the source, provide a link to the Creative Commons licence, and indicate if changes were made. The images or other third party material in this article are included in the article's Creative Commons licence, unless indicated otherwise in a credit line to the material. If material is not included in the article's Creative Commons licence and your intended use is not permitted by statutory regulation or exceeds the permitted use, you will need to obtain permission directly from the copyright holder. To view a copy of this licence, visit http://creativecommons.org/licenses/by/4.0/ The Creative Commons Public Domain Dedication waiver (http://creativecommons.org/publicdomain/zero/1.0/) applies to the data made available in this article, unless otherwise stated in a credit line to the data. 


\section{Background}

Cardiovascular diseases are a major cause of death in dialysis patients $[1,2]$, and chronic kidney diseasemineral and bone disorder (CKD-MBD) is an important risk factor of dialysis $[3,4]$. It has been reported that the management of CKD-MBD is crucial not only for dialysis patients but also for non-dialysis patients [5]. Therefore, the diagnosis and treatment guidelines of CKD-MBD were created with inputs from several countries and regions, including Japan, to establish the recommended levels of calcium (Ca), phosphorus (P), and parathyroid hormone (PTH) with the goal of the appropriate management of CKD-MBD [6-8].

Ionized $\mathrm{Ca}(\mathrm{iCa})$ is the biologically active form of $\mathrm{Ca}$ in the blood. However, considering its inconvenience and resultant high cost, there are few studies that have measured serum iCa levels in clinical settings [9]. Therefore, many guidelines do not list the recommended levels of $\mathrm{iCa}$, but list those of target total serum $\mathrm{Ca}$ or corrected $\mathrm{Ca}(\mathrm{cCa})$ levels accounting for total serum $\mathrm{Ca}$ and serum albumin (Alb) levels [6-8]. Approximately $50 \%$ of serum $\mathrm{Ca}$ is present in the form of $\mathrm{iCa}$, approximately $45 \%$ of which binds to proteins such as Alb, while the remaining $5 \%$ binds to acid to exist as $\mathrm{Ca}$ salts. Because blood iCa competes with hydrogen ions as it binds to Alb, it can be influenced by the acid-base equilibrium. During acidemia, in which the hydrogen ion concentration is increased, the quantity of $\mathrm{iCa}$ that binds to Alb decreases, resulting in higher blood iCa levels, while a lower iCa level is observed during alkalemia [10, 11].

Compared with HD patients, PD patients tend to be under metabolic alkalosis status owing to the characteristics of alkalized PD dialysate [12]. We previously reported that the acid-base equilibrium of peritoneal dialysis (PD) patients differed from that of hemodialysis (HD) patients; PD patients have a lower $\mathrm{iCa} / \mathrm{cCa}$ ratio and tend to have lower $\mathrm{iCa}$ concentrations than their HD counterparts with the same cCa levels [13]. Therefore, we reported that managing $\mathrm{Ca}$ levels based on $\mathrm{cCa}$ levels requires caution. Moreover, we compared intact PTH (iPTH) levels in PD and HD patients with equal cCa levels and found that PD patients showed higher iPTH levels than HD patients [13].

In many regions, there are more $\mathrm{HD}$ patients than $\mathrm{PD}$ patients, and the importance of the management of CKD-MBD in HD patients has been reported. However, CKD-MBD is listed as an important complication of PD as well $[14,15]$. There are several reports related to the importance of residual renal function (RRF) in managing CKD-MBD in PD patients [16-18]. The RRF of PD patients and the quantities of dialysis fluid used according to their RRF are predicted to affect their acid-base equilibria. Accordingly, differences in acid-base equilibrium among PD patients are predicted to affect the relationship between $\mathrm{iCa}$ and $\mathrm{cCa}$ levels (i.e., $\mathrm{iCa} / \mathrm{cCa}$ ratio) and its management; therefore, uniform $\mathrm{cCa}$ evaluation in $\mathrm{PD}$ patients could result in imprecise $\mathrm{iCa}$ evaluation, and its correction could not only induce the modification of the CKD-MBD treatment strategy but also reduce the risk of cardiovascular diseases, the chief outcome of CKD-MBD, in PD patients. However, there are almost no reports that have actually tested this hypothesis. Therefore, the aim of this study was to investigate the factors affecting the relationship between iCa and $\mathrm{cCa}$ levels $(\mathrm{iCa} / \mathrm{cCa}$ ratio) in $\mathrm{PD}$ patients.

\section{Methods \\ Patients}

This retrospective cross-sectional study enrolled stable patients with end-stage renal disease who were undergoing PD at Jikei University Hospital (Tokyo, Japan), Jikei University Kashiwa Hospital (Chiba, Japan), and Jikei University Katsushika Medical Center (Tokyo, Japan). They were over 20 years of age and were receiving PD treatments for more than 3 months. The exclusion criteria were as follows: ongoing combined therapy with PD and HD (6-day PD and one HD session per week) and those with the presence of acute infectious diseases, including PD-related peritonitis. Some of the patients from our previous report were also included in this study [13]. The primary objective of this study was to investigate the $\mathrm{iCa} / \mathrm{cCa}$ ratio. The study protocol was approved by the Ethics Committee of Jikei University Hospital (approval number: 30-2,959,316). Written informed consent was waived owing to the noninterventional and retrospective nature of the study. Instead, all participants were provided a means to opt out of the study.

\section{Data collection}

Patient data were obtained from April 2017 to August 2018. All blood samples, including those for blood gas analysis, were collected from the vein during regular outpatient visits. Samples were transported to the laboratory and analyzed immediately after collection. Serum iCa levels and $\mathrm{pH}$ were analyzed using the $\mathrm{ABL}$ 800 system (Radiometer, Copenhagen, Denmark) with an ion-selective electrode and $\mathrm{pH}$ electrode, respectively. Serum iPTH levels were assessed using the COBAS8000 (Roche Diagnostics GmbH, Manheim, Germany) via electrochemiluminescence immunoassay. Serum total Ca levels were measured using the TBA-2000 (Toshiba, Tokyo, Japan) with chlorophosphonazo III. Other biochemical parameters, including values of hemoglobin, creatinine, albumin, phosphorus, and C-reactive protein, were measured by standard laboratory techniques. We measured 24-h urine volume and examined weekly renal $\mathrm{Kt} / \mathrm{V}$, which were used as surrogate markers for RRF in 
this study, every 6 months as a periodical test. Blood and urine samples were collected and all biochemical parameters were measured simultaneously. Patients' clinical information, including sex, age, PD duration, body mass index (BMI), underlying disease, comorbidity, PD prescription, and medication, were also obtained during regular outpatient visits by reviewing their medical records.

Weekly renal Kt/V was calculated using the formula recommended by the Japanese Guidelines for Peritoneal Dialysis [19], which uses Watson's body fluid volume calculation [20].

Weekly renal Kt/V $=\{[$ urine urea nitrogen $(\mathrm{mg} / \mathrm{dL}) \times$ urine volume $(\mathrm{mL} /$ day $)] /[$ serum urea nitrogen $(\mathrm{mg} / \mathrm{dL}) \times$ body fluid volume $(\mathrm{L})]\} \times 7 / 1000$.

Body fluid volume for males $(\mathrm{mL})=107.4 \times$ height $(\mathrm{cm})+336.2 \times$ BW $(\mathrm{kg})+2447-95.16 \times$ age.

Body fluid volume for females $(\mathrm{mL})=106.9 \times$ height $(\mathrm{cm})+246.6 \times$ BW $(\mathrm{kg})-2097$.

Albumin-corrected Ca levels were estimated using the Payne's formula recommended in the Japanese Guidelines for CKD-MBD [8]: $\mathrm{cCa}=$ total serum $\mathrm{Ca}+$ $[4-$ serum Alb $(\mathrm{g} / \mathrm{dL})]$. Serum albumin levels of $\geq 4.0$ $\mathrm{g} / \mathrm{dL}$ indicate that $\mathrm{cCa}$ level is equal to the total serum Ca level.

\section{Statistical analysis}

Data were statistically analyzed using STATA version 16.0 (STATA Corporation, College Station, TX, USA). The patients were divided into the first, second, and third tertile of the $\mathrm{iCa} / \mathrm{cCa}$ ratio groups. Patient characteristics are presented as mean \pm standard deviation for normally distributed continuous variables, median and interquartile range for skewed continuous variables, and percentage for categorical variables. Differences among the three groups according to $\mathrm{iCa} / \mathrm{cCa}$ ratio were analyzed using one-way analysis of variance or the non-parametric Kruskal-Wallis test as appropriate. The chi-squared test or Fisher's exact test was used to compare nominal variables. The relationship between $\mathrm{iCa} / \mathrm{cCa}$ ratio and weekly renal $\mathrm{Kt} / \mathrm{V}$ in all patients was evaluated via linear regression analysis. We also divided the patients into higher or lower RRF group with the median weekly renal $\mathrm{Kt} / \mathrm{V}$ of 0.46 , and the relationship between the $\mathrm{iCa}$ and $\mathrm{cCa}$ levels of both groups were evaluated via linear regression analysis because we hypothesized that RRF has an impact on the $\mathrm{iCa} / \mathrm{cCa}$ ratio in $\mathrm{PD}$ patients. Multiple regression analysis was used to evaluate the independent factors affecting $\mathrm{iCa} / \mathrm{cCa}$ ratio. In this multivariate analysis, covariates were PD duration, weekly renal $\mathrm{Kt} / \mathrm{V}$, urinary volume, $\mathrm{pH}$, hemoglobin levels, creatinine levels, phosphate levels, and dialysate volume. Multiple imputation was performed in multiple regression analysis. The missing values of all covariates were imputed by assuming that data were missing at random with 20 imputations. PD duration, weekly renal $\mathrm{Kt} / \mathrm{V}$, urinary volume, and dialysate volume were remarkably skewed and log-transformed to normalize the distribution before multiple imputation. $P$ values of $<0.05$ were considered statistically significant.

\section{Results}

\section{Baseline characteristics}

Figure 1 summarizes the process of patient selection. The number of patients enrolled initially was 221 . After excluding patients with missing data on venous blood gas analysis and acute infectious diseases including PDrelated peritonitis as well as patients on combined therapy with PD and HD, 169 patients were enrolled in this study.

The baseline characteristics of all patients are summarized in Table 1. Patients were divided into

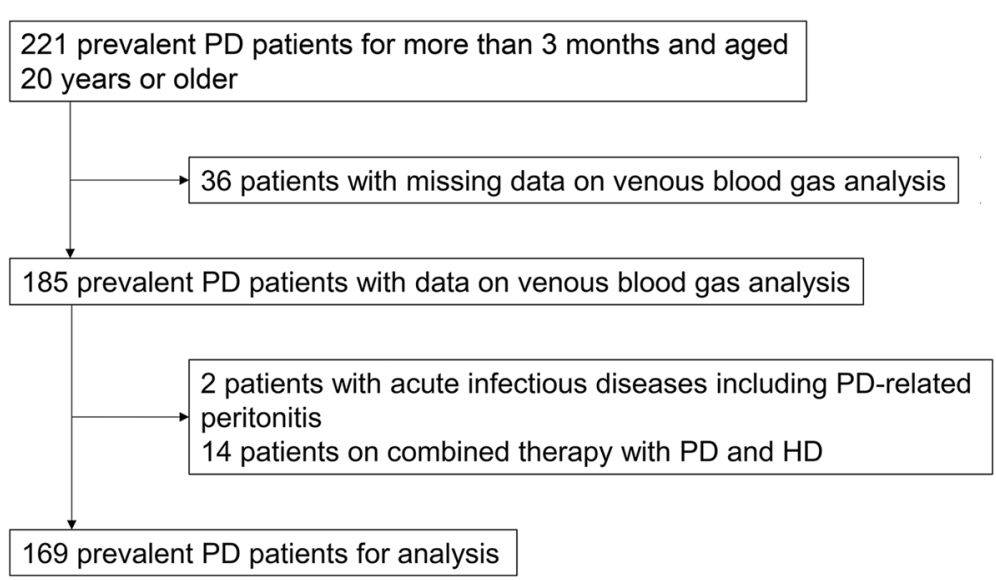

Fig. 1 Patient selection flowchart. Abbreviations: PD, peritoneal dialysis; HD, hemodialysis 
Table 1 Baseline characteristics of the 169 PD patients in our study cohort

\begin{tabular}{|c|c|c|c|c|c|c|}
\hline \multirow[t]{2}{*}{ Variable } & \multirow{2}{*}{$\begin{array}{l}\text { No. of } \\
\text { Missing } \\
\text { Value } \\
(\%)\end{array}$} & \multirow[t]{2}{*}{ Whole patients } & \multicolumn{3}{|l|}{$\mathrm{iCa} / \mathrm{cCa}$ ratio } & \multirow{2}{*}{$\begin{array}{l}P \\
\text { value }\end{array}$} \\
\hline & & & $<47.0 \%$ & 47.0 to $<49.0 \%$ & $\geq 49.0 \%$ & \\
\hline Number & $0(0)$ & 169 & $56(33 \%)$ & $54(32 \%)$ & $59(35 \%)$ & \\
\hline Male [\%] & $0(0)$ & $124(73 \%)$ & $40(71 \%)$ & 37 (69\%) & 47 (80\%) & 0.38 \\
\hline Age [y] & $0(0)$ & $62 \pm 13$ & $63 \pm 13$ & $61 \pm 14$ & $61 \pm 14$ & 0.56 \\
\hline PD duration [months] & $0(0)$ & $24(11-50)$ & $32(12-74)$ & $24(12-44)$ & $18(9-40)$ & 0.04 \\
\hline BMI $\left[\mathrm{kg} / \mathrm{m}^{2}\right]$ & $0(0)$ & $23.7 \pm 4.3$ & $22.9 \pm 4.1$ & $23.8 \pm 4.8$ & $24.5 \pm 4.0$ & 0.14 \\
\hline Underlying disease & & & & & & 0.89 \\
\hline CGN [\%] & $0(0)$ & $50(30 \%)$ & $16(28 \%)$ & $18(33 \%)$ & $16(27 \%)$ & \\
\hline Diabetes [\%] & $0(0)$ & 61 (36\%) & $21(38 \%)$ & 21 (39\%) & $19(32 \%)$ & \\
\hline Nephrosclerosis [\%] & $0(0)$ & $29(17 \%)$ & $11(20 \%)$ & $6(11 \%)$ & $12(20 \%)$ & \\
\hline PCKD [\%] & $0(0)$ & $6(4 \%)$ & $1(2 \%)$ & $2(4 \%)$ & $3(5 \%)$ & \\
\hline Others or unknown [\%] & $0(0)$ & $23(14 \%)$ & $7(13 \%)$ & $7(13 \%)$ & $9(15 \%)$ & \\
\hline \multicolumn{7}{|l|}{ Comorbidity } \\
\hline CVD [\%] & $0(0)$ & $52(31 \%)$ & 19 (34\%) & $22(41 \%)$ & $11(19 \%)$ & 0.03 \\
\hline \multicolumn{7}{|l|}{ Residual renal function } \\
\hline Urine volume [ml] & $25(14.8)$ & $700(300-1500)$ & $500(200-1080)$ & $600(190-1420)$ & $900(540-1730)$ & 0.01 \\
\hline Weekly renal Kt/N & $49(29.0)$ & $0.46(0.14-0.83)$ & $0.25(0.09-0.61)$ & $0.43(0.12-0.73)$ & $0.66(0.40-1.00)$ & $<0.01$ \\
\hline \multicolumn{7}{|l|}{ PD solution } \\
\hline Dialysate Volume [L] & $0(0)$ & $5.8 \pm 1.8$ & $6.3 \pm 1.5$ & $5.7 \pm 1.9$ & $5.5 \pm 1.9$ & 0.045 \\
\hline \multicolumn{7}{|l|}{ Medication } \\
\hline Cinacalcet [\%] & $0(0)$ & 47 (28\%) & $23(41 \%)$ & $13(24 \%)$ & $11(19 \%)$ & 0.02 \\
\hline Vitamin D [\%] & $0(0)$ & 91 (54\%) & $27(48 \%)$ & $29(54 \%)$ & 35 (59\%) & 0.49 \\
\hline Ca-containing P binder [\%] & $0(0)$ & 47 (28\%) & $23(41 \%)$ & $10(19 \%)$ & $14(24 \%)$ & 0.02 \\
\hline Ca-free P binder [\%] & $0(0)$ & $86(51 \%)$ & $26(46 \%)$ & 37 (69\%) & 23 (39\%) & $<0.01$ \\
\hline \multicolumn{7}{|l|}{ Laboratory data } \\
\hline $\mathrm{pH}$ & $0(0)$ & $7.34 \pm 0.04$ & $7.366 \pm 0.033$ & $7.339 \pm 0.005$ & $7.328 \pm 0.005$ & $<0.01$ \\
\hline Bicarbonate $[\mathrm{mmol} / \mathrm{L}]$ & $0(0)$ & $24.8 \pm 2.5$ & $25.3 \pm 2.5$ & $24.7 \pm 2.3$ & $24.3 \pm 2.5$ & 0.08 \\
\hline Hemoglobin [g/dL] & $2(1.2)$ & $11.2 \pm 1.3$ & $10.8 \pm 1.5$ & $11.1 \pm 1.1$ & $11.6 \pm 1.2$ & $<0.01$ \\
\hline Creatinine $[\mathrm{mg} / \mathrm{dL}]$ & $0(0)$ & $10.4 \pm 3.2$ & $10.7 \pm 2.8$ & $11.1 \pm 3.6$ & $9.6 \pm 2.9$ & 0.04 \\
\hline Albumin [g/dL] & $0(0)$ & $3.3 \pm 0.5$ & $2.9 \pm 0.4$ & $3.4 \pm 0.5$ & $3.5 \pm 0.3$ & $<0.01$ \\
\hline Phosphorus [mg/dL] & $0(0)$ & $5.4 \pm 1.3$ & $5.4 \pm 1.2$ & $5.5 \pm 1.6$ & $5.4 \pm 1.0$ & 0.84 \\
\hline Total Ca [mg/dL] & $0(0)$ & $8.7 \pm 0.7$ & $8.5 \pm 0.7$ & $8.6 \pm 0.6$ & $8.9 \pm 0.6$ & $<0.01$ \\
\hline $\mathrm{cCa}[\mathrm{mg} / \mathrm{dL}]$ & $0(0)$ & $9.4 \pm 0.7$ & $9.6 \pm 0.8$ & $9.3 \pm 0.6$ & $9.3 \pm 0.6$ & 0.02 \\
\hline iCa [mmol/L] & $0(0)$ & $1.13 \pm 0.09$ & $1.09 \pm 0.09$ & $1.12 \pm 0.07$ & $1.18 \pm 0.07$ & $<0.01$ \\
\hline${ }^{\mathrm{a}} \mathrm{i} C a[\mathrm{mg} / \mathrm{dL}]$ & $0(0)$ & $4.5 \pm 0.4$ & $4.6 \pm 0.3$ & $4.4 \pm 0.4$ & $4.4 \pm 0.4$ & $<0.01$ \\
\hline iCa/cCa ratio [\%] & $0(0)$ & $48.2 \pm 2.5$ & $45.4 \pm 1.5$ & $48.1 \pm 0.6$ & $50.7 \pm 1.4$ & $<0.01$ \\
\hline Intact PTH [pg/dL] & $0(0)$ & $176(103-255)$ & $180(111-269)$ & $177(121-264)$ & $151(85-233)$ & 0.54 \\
\hline CRP [mg/dL] & $0(0)$ & $0.12(0.05-0.36)$ & $0.22(0.05-0.43)$ & $0.12(0.05-0.32)$ & $0.08(0.04-0.23)$ & 0.06 \\
\hline
\end{tabular}

Abbreviations: $P D$ peritoneal dialysis, $B M I$ body mass index, $C G N$ chronic glomerulonephritis, $P C K D$ polycystic kidney disease, $C V D$ cardiovascular disease, $C a$ calcium, $c C a$ corrected calcium, $i C a$ ionized calcium, PTH parathyroid hormone, CRP C-reactive protein

${ }^{\mathrm{i}} \mathrm{i}$ Ca levels represented as $\mathrm{mg} / \mathrm{dL}$; these are the same data as above in $\mathrm{mmol} / \mathrm{L}$.

the first, second, and third tertile of the $\mathrm{iCa} / \mathrm{cCa}$ ratio groups, and their cutoff values were 47.0 and $49.0 \%$.
PD duration was longer, urine volume and weekly renal $\mathrm{Kt} / \mathrm{V}$ were lower, and dialysate volume was higher in patients with lower $\mathrm{iCa} / \mathrm{cCa}$ ratio than in those with 
higher $\mathrm{iCa} / \mathrm{cCa}$ ratio. Hemoglobin and serum albumin levels were lower, and CRP tended to be higher in the patients with lower $\mathrm{iCa} / \mathrm{cCa}$ ratio than in those with higher $\mathrm{iCa} / \mathrm{cCa}$ ratio.

Total serum $\mathrm{Ca}$ and iCa levels were significantly lower, whereas $\mathrm{cCa}$ levels and $\mathrm{pH}$ were significantly higher in the patients with lower $\mathrm{iCa} / \mathrm{cCa}$ ratio than in those with higher $\mathrm{iCa} / \mathrm{cCa}$ ratio. Notably, no between-group differences were observed in terms of serum bicarbonate, phosphorus, and iPTH levels.

\section{Relationship between the $\mathrm{iCa} / \mathrm{cCa}$ ratio and RRF}

Figure 2 shows the relationship between $\mathrm{iCa} / \mathrm{cCa}$ ratio and weekly renal $\mathrm{Kt} / \mathrm{V}$. $\mathrm{iCa} / \mathrm{cCa}$ ratio and weekly renal $\mathrm{Kt} / \mathrm{V}$ were found to be directly correlated in all study patients $(r=0.41, p<0.01)$.

\section{Relationship between iCa and $\mathrm{cCa}$ in higher and lower RRF groups}

The relationships between $\mathrm{iCa}$ and $\mathrm{cCa}$ levels of the higher and lower weekly renal $\mathrm{Kt} / \mathrm{V}$ groups are shown in Fig. 3. In both groups, iCa and $\mathrm{cCa}$ levels were directly correlated $(r=0.80, p<0.01$ and $r=0.86, p<0.01$ for higher and lower renal Kt/V groups, respectively). Figure 2 shows that at the same cCa levels, the iCa levels in patients with lower RRF were lower than those in patients with higher RRF.

\section{Independent factors affecting the relationship between iCa and cCa levels}

Table 2 shows the results for multiple regression analysis after multiple imputation, including PD duration, weekly renal $\mathrm{Kt} / \mathrm{V}, \mathrm{pH}$, hemoglobin levels, creatinine levels, phosphorus levels, and dialysate volume. Among these, weekly renal $\mathrm{Kt} / \mathrm{V}$ and $\mathrm{pH}$ were found to be independent factors affecting $\mathrm{iCa} / \mathrm{cCa}$ ratio $(\mathrm{t}=2.86, p<0.01$ and $\mathrm{t}=$ $-5.42, p<0.01$, respectively). Higher weekly renal $\mathrm{Kt} / \mathrm{V}$ corresponded to higher $\mathrm{iCa} / \mathrm{cCa}$ ratio. Furthermore, higher $\mathrm{pH}$ corresponded to lower $\mathrm{iCa} / \mathrm{cCa}$ ratio. We confirmed a similar result that $\mathrm{pH}$ and weekly renal Kt/ $\mathrm{V}$ were independent factors via multiple regression analysis using the data without imputation (Additional file 1). In addition, we selected urinary volume as a surrogate marker of RRF, instead of weekly renal Kt/V, and performed multiple regression analysis with multiple imputation (Additional file 2). Similar results as those for weekly renal $\mathrm{Kt} / \mathrm{V}$ were obtained; however, the effect of the urinary volume was a tendency $(P=0.051)$ with no significant difference.

\section{Discussion}

We observed that $\mathrm{pH}$ was higher and $\mathrm{RRF}$ was lower in $\mathrm{PD}$ patients with lower $\mathrm{iCa} / \mathrm{cCa}$ ratios. Furthermore, $\mathrm{pH}$ and $\mathrm{RRF}$ were independent factors of $\mathrm{iCa} / \mathrm{cCa}$ ratio. In PD patients with lower RRF, iCa was lower even when cCa levels were equal to those of patients with maintained RRF, suggesting that the extent of RRF requires consideration in the assessment and management of CKD-MBD in PD patients.

Our results revealed that $\mathrm{RRF}$ is an independent factor of $\mathrm{iCa} / \mathrm{cCa}$ ratio. In patients with low $\mathrm{RRF}$, high volume of $\mathrm{PD}$ dialysate could increase $\mathrm{pH}$, possibly contributing to the decreased iCa level. However, dialysis fluid volume was not an independent factor, which may indicate that $\mathrm{RRF}$ affects $\mathrm{iCa} / \mathrm{cCa}$ ratio not only based on dialysate volume but also based on multiple factors, such as elimination of acids.

There have been several reports regarding the importance of RRF in PD patients: RRF contributes to patient survival [21-25] and is associated with cardiovascular

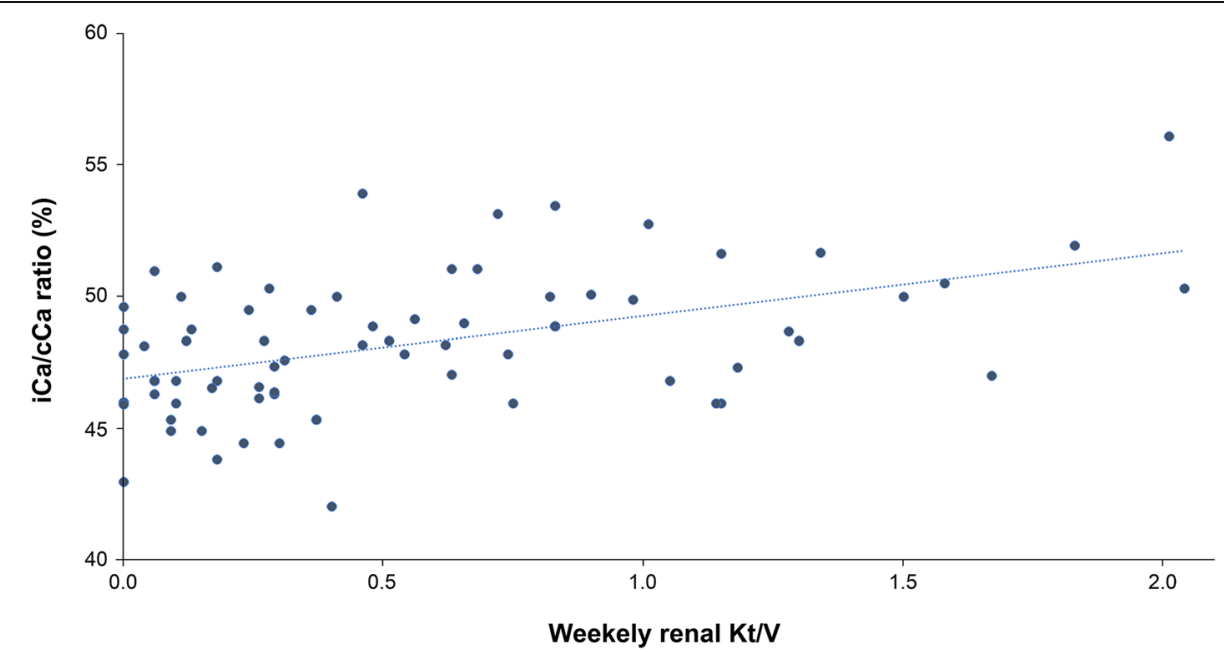

Fig. 2 Relationship between iCa/cCa ratio and weekly renal Kt/N. iCa/cCa ratio and weekly renal Kt/N were directly correlated in all 169 study patients $(r=0.41, p<0.01)$. The lower the RRF, the lower the $\mathrm{iCa} / \mathrm{CCa}$ ratio in the subjects in this study 


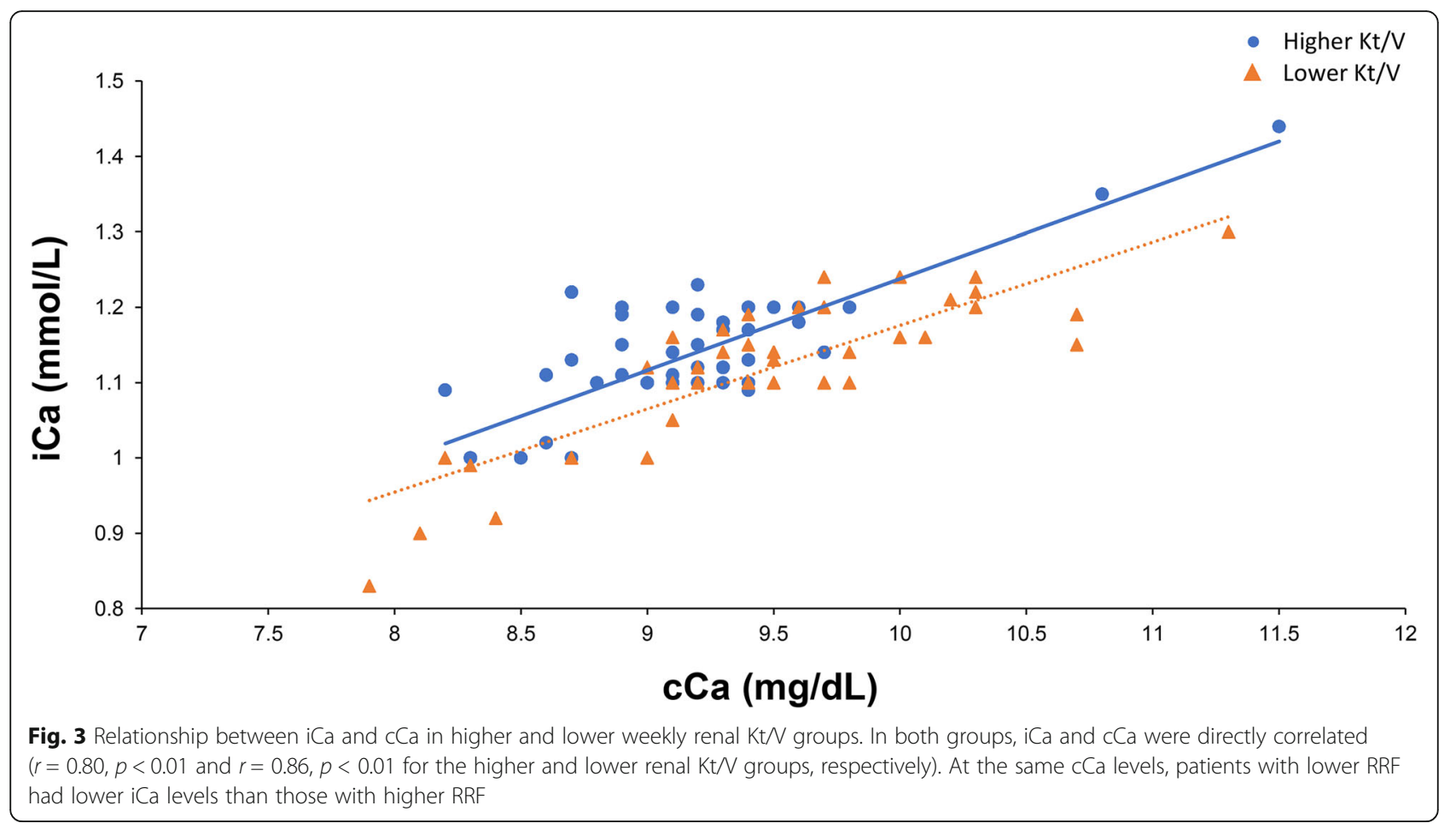

diseases [26, 27], nutritional state [28-30], and the incidence of peritonitis [31, 32]. In HD patients, the association between $\mathrm{cCa}$ and $\mathrm{iCa}$ levels varies; therefore, it is possible to erroneously evaluate ionized hyper- or hypocalcemia by assessing $\mathrm{cCa}$. This has been associated with the risk of death [33]. In patients with lower RRF, the proportion of $\mathrm{iCa}$ to $\mathrm{cCa}$ levels is lower, and when making clinical judgments based on $\mathrm{cCa}$, the physiologically active iCa level could be inaccurately measured, which can induce secondary hyperparathyroidism, thereby increasing the incidence of cardiovascular diseases. Additionally, it is well known that RRF tends to be better preserved in PD patients than in HD patients after dialysis initiation [34, 35]. Therefore, it could be important to consider RRF for the management of CKD-MBD in PD patients.

In reports regarding RRF and PTH, a higher RRF in HD patients with lower iPTH levels has been reported [36-
38]. However, reports on PD patients are few, and there is no consensus on this subject. Although the difference was insignificant, patients with maintained RRF have been reported to have lower iPTH levels [39]. On the other hand, another study has reported that they have higher whole PTH levels [40]. Furthermore, another study has reported that RRF exerts an inhibitive effect on PTH levels [41]. Various factors are involved in these differing PTH levels, one of which could be $\mathrm{iCa} / \mathrm{cCa}$ ratio. However, the present investigation did not detect any significant differences between $\mathrm{iPTH}$ levels in the higher and lower $\mathrm{iCa} / \mathrm{cCa}$ ratio groups. This may be explained by the effects of pharmacotherapy, including phosphate binders, vitamin D preparations, and Ca-sensing receptor agonists, that could help to adjust PTH to target levels. The present study did not include a very large sample size, and it was impossible to adjust the data for all drugs.

Table 2 Multiple regression analysis of $\mathrm{iCa} / \mathrm{cCa}$ ratio

\begin{tabular}{|c|c|c|c|c|c|}
\hline Variable & Regression coefficient & Standard error & $\mathrm{t}$ value & $p$ value & $95 \% \mathrm{Cl}$ \\
\hline PD duration ${ }^{a}$ & -0.00159 & 0.00210 & -0.75 & 0.45 & $-0.00574-0.00257$ \\
\hline Renal Kt/N ${ }^{a}$ & 0.00579 & 0.00203 & 2.86 & $<0.01$ & $0.00177-0.00982$ \\
\hline $\mathrm{pH}$ & -0.246 & 0.045 & -5.42 & $<0.01$ & $-0.336--0.157$ \\
\hline Hemoglobin & 0.00149 & 0.00132 & 1.13 & 0.26 & $-0.00111-0.00410$ \\
\hline Creatinine & -0.000558 & 0.000752 & 0.46 & 0.46 & $-0.000928-0.00205$ \\
\hline Phosphate & -0.00305 & 0.00167 & -1.82 & 0.07 & $-0.00635-0.000250$ \\
\hline Dialysate volume ${ }^{a}$ & -0.00131 & 0.00547 & -0.24 & 0.81 & $-0.0121-0.00949$ \\
\hline
\end{tabular}

${ }^{a} \mathrm{PD}$ duration, weekly renal $\mathrm{Kt} / \mathrm{V}$, and dialysate volume are log-transformed Abbreviation: $P D$ peritoneal dialysis 
According to the results of this study, $\mathrm{pH}$ was another independent factor of $\mathrm{iCa} / \mathrm{cCa}$ ratio in $\mathrm{PD}$ patients. This result was similar to those of previous reports, which stated that iCa levels increased in patients with acidemia and decreased in those with alkalemia [10, 11]. Regarding $\mathrm{pH}$ fluctuations, it is necessary to consider not only the metabolic status change but also respiratory compensation. Respiratory compensation could affect $\mathrm{pH}$ and consequently change serum iCa concentration. On the other hand, it has been reported that the effect of $\mathrm{pH}$ changes on $\mathrm{iCa}$ concentration in respiratory changes is blunt compared with that on $\mathrm{iCa}$ concentration in metabolic changes [10]. We thus did not monitor pulmonary-related data, such as partial pressure of carbon dioxide, in this study. Additionally, the type of PD dialysate (bicarbonate or bicarbonate/lactate) could have been considered due to its influence on $\mathrm{pH}$; however, we did not have data on the type of PD dialysate.

It is assumed that the Ca concentration of the PD dialysate affects calcium metabolism, and it has been reported that serum $\mathrm{Ca}$ concentration decreases by changing $\mathrm{Ca}$ concentration from $1.75 \mathrm{mmol} / \mathrm{l}$ to 1.25 $\mathrm{mmol} / \mathrm{l}$ [42, 43]. Furthermore, because many factors affect $\mathrm{Ca}$ metabolism in PD patients, including not only PD dialysate $\mathrm{Ca}$ concentration but also the degree of RRF, administration of vitamin $\mathrm{D}$, oral administration of $\mathrm{Ca}$-containing $\mathrm{P}$ binder, and the amount of diet $\mathrm{Ca}$ oral intake, the complexity of $\mathrm{Ca}$ balance in $\mathrm{PD}$ patients has been reported [44]. In addition, short-term retention and frequent dialysate exchange in anuria APD patients suppress transperitoneal $\mathrm{Ca}$ removal has been reported [45]. As a result, we should manage serum Ca concentration in PD patients with the understanding that there are many factors that have an impact on serum $\mathrm{Ca}$ concentration. In this study, although these factors could have been considered, not all of them were monitored because the aim of this study was to investigate the factors affecting $\mathrm{iCa} / \mathrm{cCa}$ ratio and not serum $\mathrm{Ca}$ concentration.

This study has several limitations. First, it was a retrospective cross-sectional study, and its retrospective nature prevented us from making claims on causation or their directions. Second, in Japan, the rate of PD in all dialysis patients is low, approximately $3 \%$. Therefore, it was difficult to obtain a large sample size for this study, and our sample size was relatively small (169 patients). Third, because we only evaluated PD patients, it is unknown whether the relationship between $\mathrm{RRF}$ and $\mathrm{iCa} /$ $\mathrm{cCa}$ and $\mathrm{pH}$ as well as the $\mathrm{iCa} / \mathrm{cCa}$ relationship that was observed in PD patients can also be applied to HD patients and non-dialysis CKD patients. Fourth, we did not have the data of a high- or low-calcium dialysate, values of 1,25-dihydroxy vitamin D and 25-hydroxyvitamin D, and the type of peritoneal transport. Finally, the findings of the present study cannot be reflected in other populations because the distribution of primary kidney disease and several environmental factors differ based on races or regions of the world [46].

\section{Conclusions}

$\mathrm{PD}$ patients with a lower $\mathrm{iCa} / \mathrm{cCa}$ ratio showed higher $\mathrm{pH}$ value and reduced RRF. Furthermore, $\mathrm{pH}$ and RRF were both independent factors of $\mathrm{iCa} / \mathrm{cCa}$ ratio. $\mathrm{iCa}$ levels were lower in PD patients with reduced RRF, even if their $\mathrm{cCa}$ levels were equal to those of patients with maintained RRF. Therefore, for PD patients, the use of cCa alone to perform an assessment of CKD-MBD could result in under- or overestimation of iCa levels, leading to poor management of the disease. CKD-MBD should be cautiously managed on the basis of this difference in daily clinical practice in PD patients for the better management of CKD-MBD as well as for reducing the risk of cardiovascular diseases. Further research investigating the mortality and incidence of complications associated with CKD-MBD in large sample sizes are warranted to develop this study's findings.

\section{Supplementary information}

Supplementary information accompanies this paper at https://doi.org/10. 1186/s12882-020-02033-y.

Additional file 1. Multiple regression analysis of $\mathrm{iCa} / \mathrm{cCa}$ ratio without imputation. Using multiple regression analysis of the data without imputation, we confirmed that $\mathrm{pH}$ and weekly renal $\mathrm{Kt} / \mathrm{N}$ were independent factors affecting iCa/cCa ratio.

Additional file 2. Multiple regression analysis of $\mathrm{iCa} / \mathrm{cCa}$ ratio with multiple imputation, including urinary volume as a surrogate marker of $\mathrm{RRF}$ instead of weekly renal $\mathrm{Kt} / \mathrm{N}$. $\mathrm{pH}$ was an independent factor affecting $\mathrm{iCa} / \mathrm{cC}$ a ratios. Urinary volume has a tendency to affect $\mathrm{iCa} / \mathrm{cCa}$ ratio, although it was not significant

\section{Abbreviations}

Alb: Albumin; cCa: Corrected calcium; CKD-MBD: Chronic kidney diseasemineral and bone disorder; HD: Hemodialysis; iCa: Ionized Ca; iPTH: Intact parathyroid hormone; PD: Peritoneal dialysis; PTH: Parathyroid hormone; RRF: Residual renal function

\section{Acknowledgements}

Not applicable.

\section{Authors' contributions}

Conception and design of the study: MM, YM, MN, NM, and IO. Data collection: MM, YM. Statistical analysis: MM and YM. Analysis and interpretation of data: MM, YM, NM, YT, IO, MI, and TY. Drafting of the manuscript: MM and YM. Critical review of the manuscript: MI and TY. All authors have read and approved the final version of the manuscript.

\section{Authors' information}

Affiliation.

Division of Nephrology and Hypertension, Department of Internal Medicine, The Jikei University School of Medicine, Tokyo, Japan.

Academic qualifications:

MM, M.D.; YM, M.D. and Ph.D.; MN, M.D. and Ph.D.; NM, M.D. and Ph.D.; YT, M.D.; IO, M.D. and Ph.D.; MI, M.D. and Ph.D.; and TY, M.D. and Ph.D. 


\section{Funding}

This research received no specific grant from any funding agency in the public, commercial, or not-for-profit sectors.

\section{Availability of data and materials}

The datasets used and/or analyzed during the current study are available from the corresponding author upon reasonable request.

\section{Ethics approval and consent to participate}

The study protocol was approved by the Ethics Committee of The Jikei University Hospital (approval number: 30-295 9316). All individual participants were provided a means to opt out of the study.

\section{Consent for publication}

Not applicable.

\section{Competing interests}

Y.M. and M.I. received scholarship funds from Baxter International, Inc. and Terumo Corporation. Y.T. received research grants from Baxter Healthcare Corporation, Inc. No sources of funding had any direct involvement in the design or conduct of the study; collection, management, analysis, or interpretation of the data; or the preparation, review, or approval of the manuscript. No other authors have any conflicts of interest to declare.

Received: 20 November 2019 Accepted: 20 August 2020

Published online: 26 August 2020

\section{References}

1. Schiffrin EL, Lipman ML, Mann JF. Chronic kidney disease: effects on the cardiovascular system. Circulation. 2007;116:85-97.

2. Saran R, Robinson B, Abbott KC, Agodoa LYC, Bragg-Gresham J, Balkrishnan $R$, et al. US renal data system 2018 annual data report: epidemiology of kidney Disease in the United States. Am J Kidney Dis. 2019;73:A7-8.

3. Shlipak MG, Fried LF, Cushman M, Manolio TA, Peterson D, Stehman-Breen $C$, et al. Cardiovascular mortality risk in chronic kidney disease: comparison of traditional and novel risk factors. JAMA. 2005:293:1737-45.

4. Fujii $\mathrm{H}$, Joki N. Mineral metabolism and cardiovascular disease in CKD. Clin Exp Nephrol. 2017:21:53-63.

5. Gallieni M, De Luca N, Santoro D, Meneghel G, Formica M, Grandaliano G, et al. Management of CKD-MBD in non-dialysis patients under regular nephrology care: a prospective multicenter study. J Nephrol. 2016;29:71-8.

6. National Kidney Foundation. KJOOI clinical practice guidelines for bone metabolism and disease in chronic kidney disease. Am J Kidney Dis. 2003; 42:51-201.

7. Disease K. Improving Global Outcomes CKD-MBD Work Group. KDIGO clinical practice guideline for the diagnosis, evaluation, prevention, and treatment of chronic kidney disease-mineral and bone disorder (CKD-MBD). Kidney Int Suppl. 2009;113:S1-130.

8. Fukagawa M, Yokoyama K, Koiwa F, Taniguchi M, Shoji T, Kazama JJ, et al. Clinical practice guideline for the management of chronic kidney diseasemineral and bone disorder. Ther Apher Dial. 2013;17:247-88.

9. Calvi LM, Bushinsky DA. When is it appropriate to order an ionized calcium? J Am Soc Nephrol. 2008;19:1257-60

10. Oberleithner $H$, Greger $R$, Lang $F$. The effect of respiratory and metabolic acid-base changes on ionized calcium concentration: in vivo and in vitro experiments in man and rat. Eur J Clin Investig. 1982;12:451-5.

11. Wang S, McDonnell EH, Sedor FA, Toffaletti JG. pH effects on measurements of ionized calcium and ionized magnesium in blood. Arch Pathol Lab Med. 2002;126:947-50

12. Vashistha T, Kalantar-Zadeh K, Molnar MZ, Torlén K, Mehrotra R. Dialysis modality and correction of uremic metabolic acidosis: relationship with allcause and cause-specific mortality. Clin J Am Soc Nephrol. 2013;8:254-64.

13. Morishita M, Matsuo N, Maruyama Y, Nakao M, Yamamoto I, Tanno Y, et al. The differences in acid-base status and the calcium parathyroid axis between peritoneal dialysis and hemodialysis. Clin Nephrol. 2016;86:55-61.

14. Shang D, Xie Q, Ge X, Yan H, Tian J, Kuang D, et al. Hyperphosphatemia as an independent risk factor for coronary artery calcification progression in peritoneal dialysis patients. BMC Nephrol. 2015;16:107.

15. Noordzij M, Korevaar JC, Bos WJ, Boeschoten EW, Dekker FW, Bossuyt PM, et al. Mineral metabolism and cardiovascular morbidity and mortality risk: peritoneal dialysis patients compared with haemodialysis patients. Nephrol Dial Transplant. 2006;21:2513-20.

16. Wang AY, Woo J, Sea MM, Law MC, Lui SF, Li PK. Hyperphosphatemia in Chinese peritoneal dialysis patients with and without RRF kidney function: what are the implications? Am J Kidney Dis. 2004;43:712-20.

17. Wang $A Y$, Lai $K N$. The importance of residual renal function in dialysis patients. Kidney Int. 2006;69:1726-32.

18. Rroji M, Seferi S, Cafka M, Petrela E, Likaj E, Barbullushi M, et al. Is residual renal function and better phosphate control in peritoneal dialysis an answer for the lower prevalence of valve calcification compared to hemodialysis patients? Int Urol Nephrol. 2014;46:175-82.

19. Working Group Committee for Preparation of Guidelines for Peritoneal Dialysis, Japanese Society for Dialysis Therapy; Japanese Society for Dialysis Therapy. 2009 Japanese Society for Dialysis Therapy guidelines for peritoneal dialysis. Ther Apher Dial. 2010;14:489-504.

20. Watson PE, Watson ID, Batt RD. Total body water volumes for adult males and females estimated from simple anthropometric measurements. Am J Clin Nutr. 1980;33:27-39.

21. Rocco M, Soucie JM, Pastan S, McClellan WM. Peritoneal dialysis adequacy and risk of death. Kidney Int. 2000;58:446-57.

22. Bargman JM, Thorpe KE, Churchill DN. Relative contribution of residual renal function and peritoneal clearance to adequacy of dialysis: a reanalysis of the CANUSA study. J Am Soc Nephrol. 2001;12:2158-62.

23. Rocco MV, Frankenfield DL, Prowant B, Frederick P, Flanigan MJ. Risk factors for early mortality in US peritoneal dialysis patients: impact of residual renal function. Perit Dial Int. 2002;22:371-9.

24. Termorshuizen F, Korevaar JC, Dekker FW, van Manen JG, Boeschoten EW, Krediet RT. The relative importance of residual renal function compared with peritoneal clearance for patient survival and quality of life: an analysis of the Netherlands cooperative study on the adequacy of Dialysis (NECOSAD)-2. Am J Kidney Dis. 2003;41:1293-302.

25. Wang AY, Woo J, Wang M, Sea MM, Sanderson JE, Lui SF, et al. Important differentiation of factors that predict outcome in peritoneal dialysis patients with different degrees of residual renal function. Nephrol Dial Transplant. 2005;20:396-403.

26. Wang AY, Wang M, Woo J, Law MC, Chow KM, Li PK, et al. A novel association between residual renal function and left ventricular hypertrophy in peritoneal dialysis patients. Kidney Int. 2002;62:639-47.

27. Wang AY, Wang M, Woo J, Lam CW, Lui SF, Li PK, et al. Inflammation, residual kidney function, and cardiac hypertrophy are interrelated and combine adversely to enhance mortality and cardiovascular death risk of peritoneal dialysis patients. J Am Soc Nephrol. 2004;15:2186-94.

28. Suda T, Hiroshige K, Ohta T, Watanabe Y, Iwamoto M, Kanegae K, et al. The contribution of residual renal function to overall nutritional status in chronic haemodialysis patients. Nephrol Dial Transplant. 2000;15:396-401.

29. Szeto CC, Lai KN, Wong TY, Law MC, Leung CB, Yu AW, et al. Independent effects of residual renal function and dialysis adequacy on nutritional status and patient outcome in continuous ambulatory peritoneal dialysis. Am J Kidney Dis. 1999;34:1056-64.

30. Wang AY, Sea MM, Ip R, Law MC, Chow KM, Lui SF, et al. Independent effects of residual renal function and dialysis adequacy on actual dietary protein, calorie, and other nutrient intake in patients on continuous ambulatory peritoneal dialysis. J Am Soc Nephrol. 2001;12: 2450-7.

31. Pérez Fontan M, Rodríguez-Carmona A, García Naveiro R, Rosales M, Villaverde $\mathrm{P}$, Valdés F. Peritonitis-related mortality in patients undergoing chronic peritoneal dialysis. Perit Dial Int. 2005;25:274-84.

32. Han SH, Lee SC, Ahn SV, Lee JE, Kim DK, Lee TH, et al. Reduced residual renal function is a risk factor for peritonitis in continuous ambulatory peritoneal dialysis patients. Nephrol Dial Transplant. 2007;22:2653-8.

33. Obi Y, Mehrotra R, Rivara MB, Streja E, Rhee CM, Lau WL, et al. Hidden hypercalcemia and mortality risk in incident hemodialysis patients. J Clin Endocrinol Metab. 2016;101:2440-9.

34. Lang SM, Bergner A, Töpfer M, Schiffl H. Preservation of residual renal function in dialysis patients: effects of dialysis-technique-related factors. Perit Dial Int. 2001;21:52-7.

35. Moist LM, Port FK, Orzol SM, Young EW, Ostbye T, Wolfe RA, et al. Predictors of loss of residual renal function among new dialysis patients. J Am Soc Nephrol. 2000;11:556-64.

36. Penne EL, van der Weerd NC, Grooteman MP, Mazairac AH, van den Dorpel MA, Nubé MJ, et al. Role of residual renal function in phosphate control and 
anemia management in chronic hemodialysis patients. Clin J Am Soc Nephrol. 2011;6:281-9.

37. Wang M, Obi Y, Streja E, Rhee CM, Lau WL, Chen J, et al. Association of parameters of mineral bone disorder with mortality in patients on hemodialysis according to level of residual kidney function. Clin J Am Soc Nephrol. 2017;12:1118-27.

38. Wang M, You L, Li H, Lin Y, Zhang Z, Hao C, et al. Association of circulating fibroblast growth factor-23 with renal phosphate excretion among hemodialysis patients with residual renal function. Clin J Am Soc Nephrol. 2013;8:116-25

39. Li L, Liang W, Ye T, Chen Z, Zuo X, Du X, et al. The association between nutritional markers and biochemical parameters and residual renal function in peritoneal dialysis patients. PLoS One. 2016;11:e0156423.

40. Yamada S, Tsuruya K, Taniguchi M, Yoshida H, Tokumoto M, Hasegawa S, et al. Relationship between residual renal function and serum fibroblast growth factor 23 in patients on peritoneal dialysis. Ther Apher Dial. 2014;18: 383-90.

41. Okada S, Inoue T, Nakamoto H, Ikeda N, Sugahara S, Shoda J, et al. Residual renal function plays an important role in regulating parathyroid hormone in patients on continuous ambulatory peritoneal dialysis. Adv Perit Dial. 2007; 23:150-4.

42. Sun J, Wang R, Yu K, Wang Q, Wang X. The effect of low calcium dialysate on calcium-phosphate metabolism and its correlation with other coefficient factors in CAPD. Dial Transplant. 2009:38:320-3.

43. Jin L, Zhou J, Shao F, Yang F. Long-term effects on PTH and mineral metabolism of 1.25 versus $1.75 \mathrm{mmol} / \mathrm{L}$ dialysate calcium in peritoneal dialysis patients: a meta-analysis. BMC Nephrol. 2019;20:213.

44. Wang AY. Calcium balance and negative impact of calcium load in peritoneal dialysis patients. Perit Dial Int. 2014;34:345-52.

45. Hamada C, Tomino Y. Transperitoneal calcium balance in anuric continuous ambulatory peritoneal dialysis and automated peritoneal dialysis patients. Int J Nephrol. 2013;2013:863791.

46. AlYousef A, AlSahow A, AlHelal B, Alqallaf A, Abdallah E, Abdellatif M, et al. Glomerulonephritis histopathological pattern change. BMC Nephrol. 2020; 21:1-7.

\section{Publisher's Note}

Springer Nature remains neutral with regard to jurisdictional claims in published maps and institutional affiliations.

Ready to submit your research? Choose BMC and benefit from:

- fast, convenient online submission

- thorough peer review by experienced researchers in your field

- rapid publication on acceptance

- support for research data, including large and complex data types

- gold Open Access which fosters wider collaboration and increased citations

- maximum visibility for your research: over $100 \mathrm{M}$ website views per year

At $\mathrm{BMC}$, research is always in progress.

Learn more biomedcentral.com/submissions 